\title{
Article \\ Introducing the Living Lab Approach in the Coastal Area of Constanta (Romania) by Using Design Thinking
}

\author{
Catalin Anton *, Angela Eliza Micu (D) and Eugen Rusu (D)
}

check for updates

Citation: Anton, C.; Micu, A.E.; Rusu,

E. Introducing the Living Lab

Approach in the Coastal Area of

Constanta (Romania) by Using

Design Thinking. Inventions 2022, 7,

19. https://doi.org/10.3390/

inventions7010019

Academic Editor: Volker Hessel

Received: 31 October 2021

Accepted: 26 January 2022

Published: 29 January 2022

Publisher's Note: MDPI stays neutral with regard to jurisdictional claims in published maps and institutional affiliations.

Copyright: (C) 2022 by the authors. Licensee MDPI, Basel, Switzerland. This article is an open access article distributed under the terms and conditions of the Creative Commons Attribution (CC BY) license (https:// creativecommons.org/licenses/by/ $4.0 /$ )
Doctoral School of Socio-Human Sciences, Dunarea de Jos University of Galati, 47 Domneasca Street, 800008 Galati, Romania; angela-eliza.micu@365.univ-ovidius.ro (A.E.M.); eugen.rusu@ugal.ro (E.R.)

* Correspondence: catanton@gmail.com

Abstract: Living Labs are an innovative concept that combines research, governance, and citizens, using technology and knowledge. Using design thinking techniques as a method of approach, this innovative idea builds a bridge between decision makers and stakeholders, promoting a shared vision of growth and innovation at the community level. The coastal zone is an extremely dynamic area in terms of human and natural activities. This is a particularly sensitive area to climate change, necessitating ongoing adaptation and mitigating action. This paper aims to introduce the application of the Living lab concept in the management of the coastal area of Constanta (Romania). The concept of the Living Lab means involving citizens along with public bodies and research structures. This new coastal management model will use the design thinking approach and will consider the pressures that exist between the activities that occur in the examined coastal zone. In the study, "Multi-Criteria Analysis of the Mass Tourism Management Model Related to the Impact on the Local Community in Constanța (Romania)", published in MDPI Inventions on 28 June 2021, a coastal management model was built that took into consideration only the data given by the government. In this paper, the authors aim to expand their research by including data from independent sources, using the concept of a Living Lab.

Keywords: living labs; design thinking; management model; coastal zone; integrated coastal zone management (ICZM); Constanta; Black Sea; sustainability

\section{Introduction}

Unlike the typical structure of global society, the coastline is a vibrant socio-ecological environment. The purpose of integrated coastal zone management (ICZM) is to design a sustainable development model that focuses on, surrounds, and incorporates a number of essential elements (economic, social and environmental). The Romanian Black Sea coast is currently under threat, mainly due to human pressures that have accumulated over time. The agricultural and industrial sectors of the economy have often developed in a chaotic manner. Coastal erosion has now been discovered to be under severe stress, with the possibility of sea infiltration into land areas. Excessive resource use will result in the devastation of the natural terrestrial and aquatic ecosystems. In the future, while addressing the negative effects of climate change, it will be necessary to seek adaptive or alternative solutions [1-3].

Integrated coastal zone management is a complex strategic management mechanism that requires the participation of all stakeholders and the general public at the national, regional, and local levels. The "strategic integration" of coastal development plans will be established by creating the organizational and legal framework, tools, and procedures required to ensure the best combination (integration) of coastal development plans.

Integrated coastal zone management (ICZM) is a social, ecological structure with extremely complex characteristics due to differences in society, culture, finance, nature, and governance. The ICZM's mission is to promote integrated coastal zone management 
by investigating the relationship between coastal zone management and governance variables $[4,5]$.

Traditional coastal management is generally achieved through a linear approach based on an up-down pyramid decision-making structure. The hierarchical structure is reduced to governmental political entities, while the other existing actors in the coastal zone (small and medium enterprizes, academia, research institutes, citizens, etc.) are called stakeholders, and the way of involving the latter is smaller or larger depending on the decision of the authorities. The linear approach has a predominantly hierarchical and less consultative decision-making role. Living labs have emerged in Europe in recent years to become closer with citizens and to facilitate collaboration between different stakeholder groups. These mechanisms collect creative ideas and work skills in order to involve private users, together with public bodies, to improve the environment within communities. Approaching the concept of a Living Lab in coastal management can be beneficial because this structure aims to involve citizens along with public bodies and research structures. Through the design thinking approach technique, coastal Living Labs will identify, define, develop, test, or validate new development policies, projects, and community strategies. The implementation framework of a Living Lab in the coastal area is a centric one, starting from the observations of the citizens and of the scientific environment, which define, conceptualize, and test the existing vulnerabilities in that area. The role of decision makers is to take these observations and research results and turn them into public policies. To create this functional framework, the authors consider it essential to involve citizens, through the data they provide, both in research and development. A Living Lab implemented in a coastal area can only benefit the community. As it is currently defined, integrated coastal management entails a collaboration between the scientific component and the public/human component. The public policies of the area are created by combining these two components, and the management component of ICZM is carried out (Figure 1) [6-10].

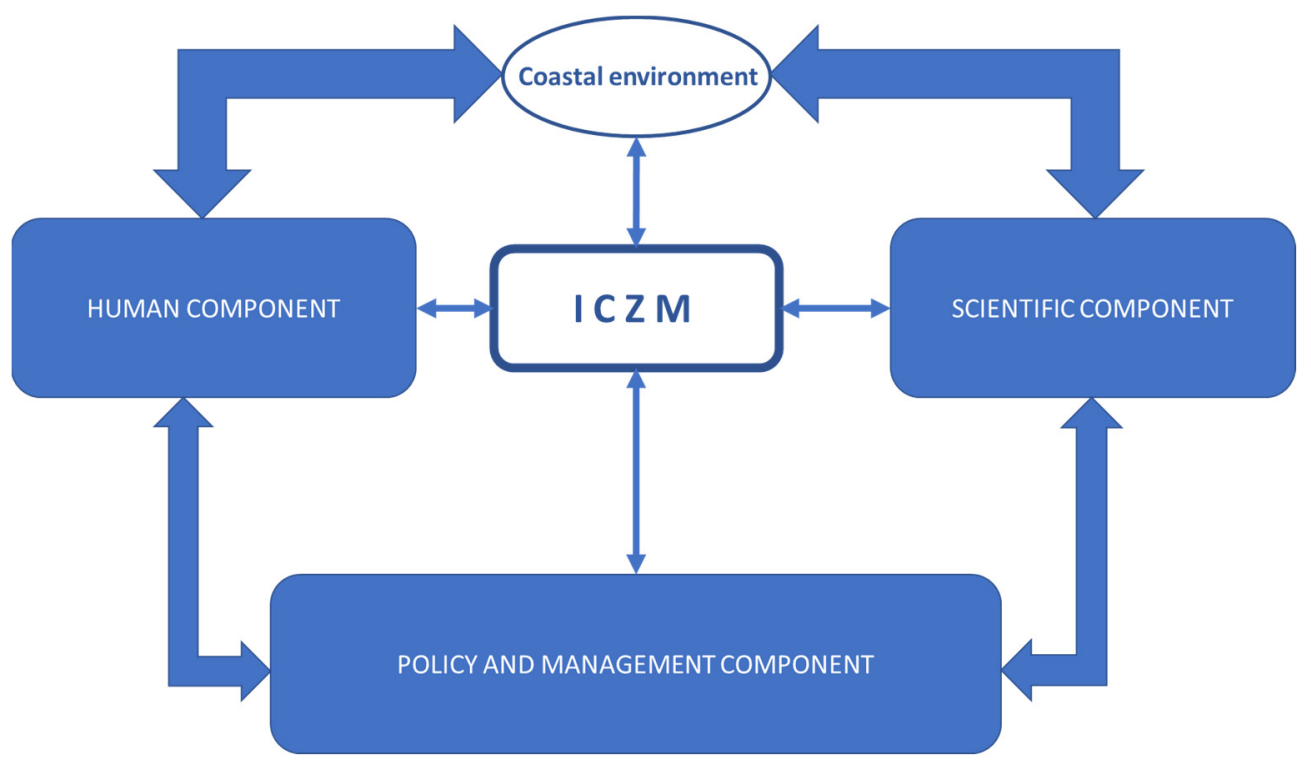

Figure 1. Diagram of the integrated coastal zone management process. Source: author after Rutger de Graaf-van Dinther (editor), Climate-Resilient Urban Areas' Governance, Design, and Development in Coastal Delta Cities.

Romania has taken small steps toward implementing integrated coastal management. Even though specific legislation has been in place since 2002, the organizational structure and decision-making process are limited to the adoption of consultative points of view that use authorities in the decision-making process [11-13]. As a result, establishing a Living Lab in the coastal area can help in actively involving stakeholders in decision making [14]. 
Given the foregoing, we may infer that the stage at which this paper is written represents a linear approach to integrated coastal management. The gap is the innovative Living Lab method in Europe, which may fill a void for the Constanta coastal area. The methodology we use is the design thinking method, and the innovation consists in enhancing data collection through citizen science and combining academic research resources as well as businesses development resources.

\section{Materials and Methods}

The creation of a "Living Lab" in coastal areas must consider a citizen-centered approach to research and development, taking into account technological innovations [10,12]. This type of approach will facilitate the interaction between stakeholders, bringing together all actors in the coastal area, whether we are talking about academia, the civic sector, state actors, or the business sector. A "Living Lab" is a new and dynamic body that brings technical research into real-world collaborative environments. The new concept has several principles by which it is defined [9,15-17], namely:

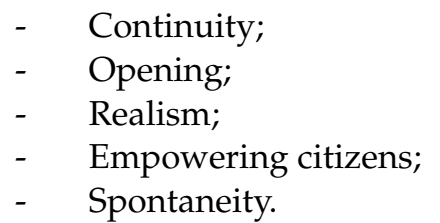

To explain these principles, it must be said that a Living Lab is based on creativity and innovation, but also on a good multidisciplinary collaboration. The innovative process must be credible and as open as possible, and at the same time it needs time to be structured. The multi-criteria approach of the newly created Living Labs is essential to provide a multi-perspective vision. The central element of the new structures is the citizen and his involvement in the innovation processes. Users are the ones who benefit from innovations and guide them to satisfy their own desires and needs. The more inventive the user communities are, the more efficient Living Labs become at achieving their intended purpose. Traditional coastal management systems have a linear approach, unlike the Living Labs structure, which has a centered approach [17]. The analysis of these systems is of mixed type, having qualitative elements but also emphasizing the quantitative side $[18,19]$. The aim of the authors is to show the usefulness of a mixed paradigm in coastal management research. We aim to maximize our strengths and weaken our strengths through this form of research and not to replace any of the particularly useful and important forms of classical research, including both quantitative and qualitative. The paradigm of mixed-method research, as in this paper, minimizes the schism between qualitative and quantitative approaches to research.

If we are to better understand this concept of the mixed research method, we can say that this new type combines methods and techniques, concepts, and qualitative or quantitative approaches in a single study.

The process involves the combination of three primary factors, namely, induction, deduction, and abduction. This means, in research practice, that models must be identified and theories tested, validated, and conceptualized. Therefore, traditional approaches to integrated coastal management are generally linear and often cyclical (Figure 2). Living Labs, on the other hand, takes a design-based approach with a focus on loop development (Figure 3) [20-24]. 


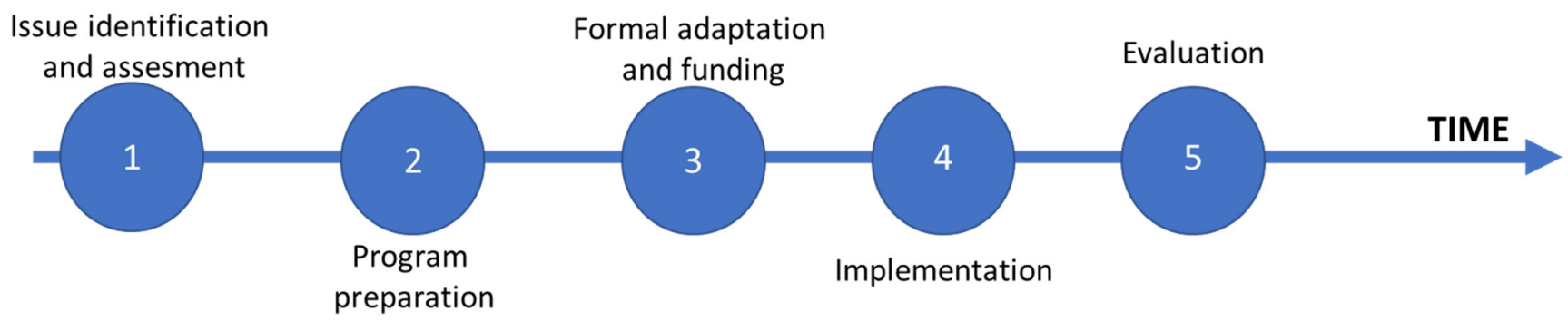

Figure 2. The conventional approach to integrated coastal management systems.

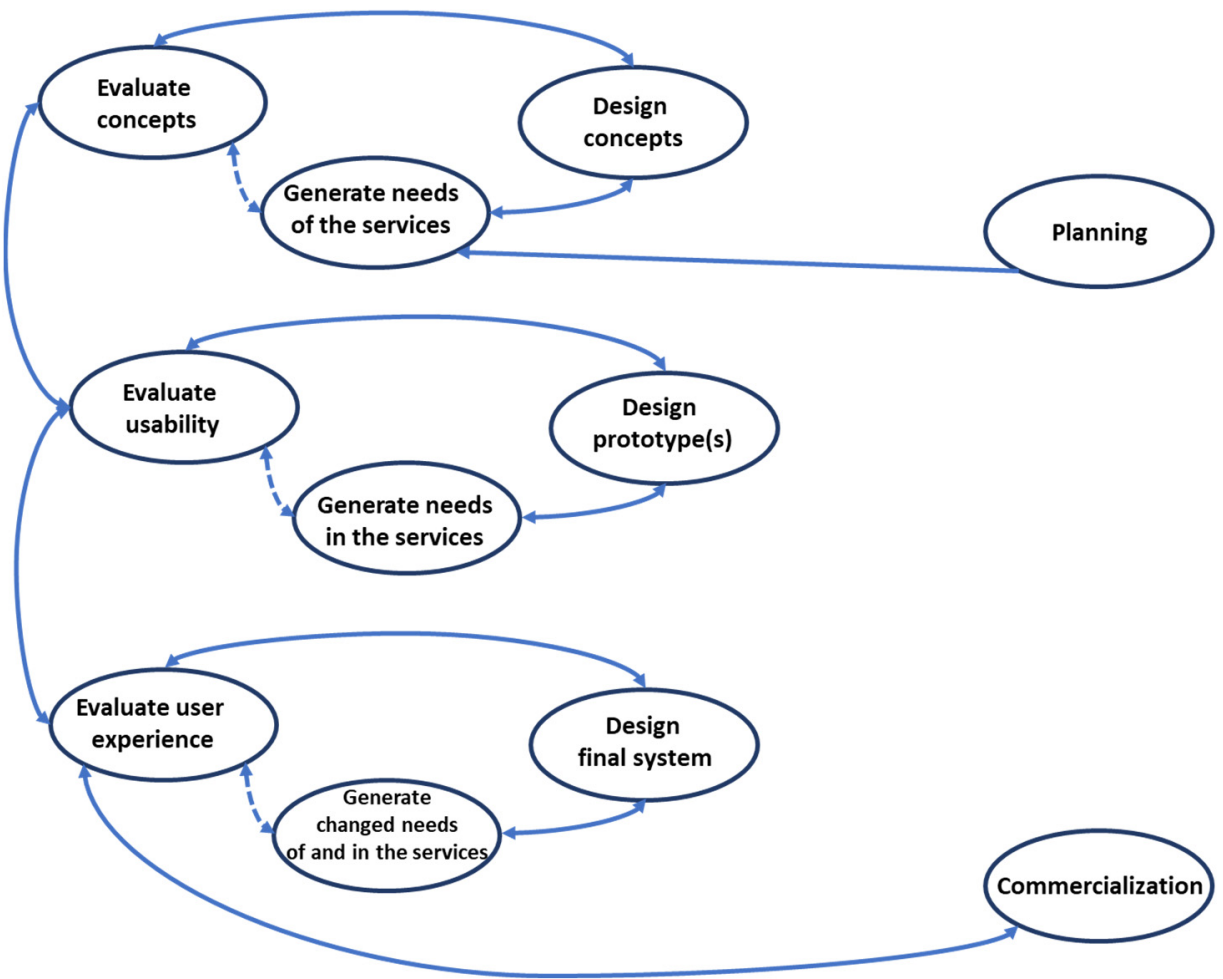

Figure 3. The in-system loop approach of Living Labs.

Perhaps the most obvious distinction between integrated linear coastal zone management and the Living Lab is based on conceptual realism. If the classical linear form has a theoretical and formal vision, a Living Lab is much more pragmatic, contextualizing real-world facts and attitudes. Even from the users' point of view, the two management systems are fundamentally different [16]. If, in the case of linear vision, users are formal and well-structured, with clear and precise attributes, in the case of Living Labs, these users are creative, informal, but deeply rooted in current reality. Therefore, in the case of Living Labs, users are urged to create in the most authentic contexts, under the observation of researchers and developers involved in the process $[8,10,25]$. The paradigm of mixed research in the case of Living Labs shows that users are considered as partners in the coastal management process, while in the case of traditional systems, they are considered as actors, the approach being organizational [26]. This element is a defining one in differentiating the two systems, showing that Living Labs has, as its central element, the citizen and his empowerment to the detriment of a formal organization [27-29]. This means that the new approach of Living Labs emphasizes the spontaneity and inventiveness of the citizens involved. Another important point is the relationship with the academic environment, which, in the case of the new approach, is a close one, with citizens using the research results, while in traditional systems, this type of connection is not always made [30]. That is why the new structures could use this to investigate both theoretical and practical problems. 
Specifically, research is conducted in the Living Labs environment, while in traditional classical systems, the academic environment conducts research at the express request of decision makers, if any [31].

As previously stated, the approach to introducing a Living Lab in the coastal zone is a design thinking technique. This is also because design thinking involves a human-centered vision of innovation, which seeks to establish creative ideas and effective business models that are focused on people's needs [11,12]. The basic idea behind design thinking is that you apply designer approaches and methods to the development of innovations (this is what the word "design" means), while conducting a systematic, fact-based analysis of the economic feasibility and viability of these innovations-just like a researcher (this is what the "thinking" part of the term represents).

In the case of Living Labs, the research identifies citizens' problems or desires and considers them from the perspective of their target users. Designers use this knowledge to generate the first user-oriented ideas, visualize their creative solutions at an early stage, and then create prototypes. They quickly solicit community feedback and modify their concept as a result. Designers address the best solution for their target users' step by step. The project's approach and individual methods are supplemented by a mindset that intentionally analyzes the product's feasibility and economic viability during development [13].

To address social challenges such as climate change, population growth, food security, health, mobility, and energy supply, new ideas are required. These concepts are central to economic growth. Some ideas become global standards, while others fill niches in local and regional markets. Design thinking assists coastal managers in creative problem solving, regardless of the size of the problem. The method can be applied to a wide range of questions. These may include new products, services, business models, or social and organizational concepts $[9,11]$.

Several principles must be followed in design thinking to ensure success [10]:

» Developing empathy: Investigating the emotions, thoughts, intentions, and actions of users;

» Illustration of ideas: Imagining ideas and illustrating them with a prototype for potential users to try;

» Learning from failure: Creating a culture that recognizes the value of mistakes, so that they are tolerated and learned from;

» Ensuring diversity: Age, gender, education, culture, and personality type all contribute to diversity;

» Creating creative and team-oriented workspaces: Spaces for individual and group work, along with spaces for the entire group, must be designed to be adaptable and inspiring;

» Process flexibility: The design mindset encourages a methodical approach. This procedure includes steps relating to problem analysis, such as formulating a task, developing possible initial solutions, testing them, and learning from feedback.

Figure 4 depicts the stages of the design thinking process.

If the design thinking process within a Living Lab can lead to the identification and evaluation of a coastal activity, these activities must be attributed to economic, social, or environmental factors. Because of the complexity of coastal areas, some activities are competitive while others are complementary. This type of activity, as well as the impact it generates, can be accurately identified using the design thinking process [12].

The basic identification of activities in terms of their social and environmental economic factors, in our opinion, is incomplete to carry out an effective analysis that will serve as the foundation for a sustainable coastal management model. By recognizing the interaction between indicators, one can demonstrate the dependence of some activities on others, as well as the areas where the interaction of these activities creates conflict that can result in coastal zone vulnerability [1,2]. 


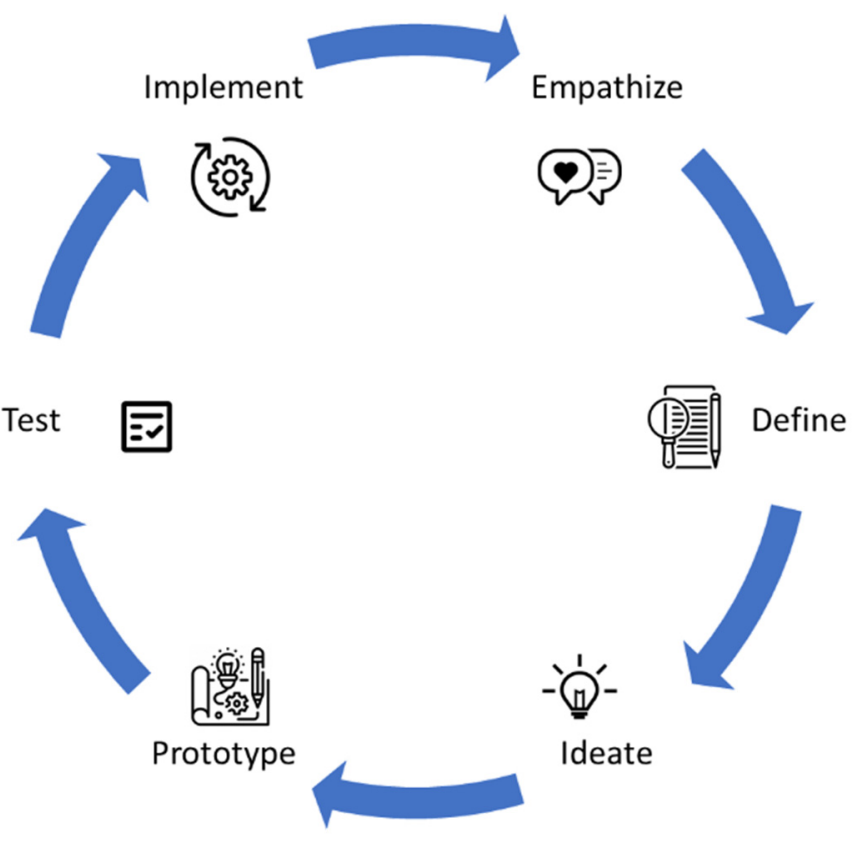

Figure 4. The stages of the design thinking process. Source: image processed after Christian MüllerRoterberg-Design Thinking.

We used the concept of a supportability factor to measure the interaction between these activities. This tool shows the value at which one of the activities can exist without causing the other to disintegrate. The supportability factor for activities that have affected each other reaches zero, depending on the greater or lesser impact between the activities. Furthermore, if one activity had a positive effect on the other, the supportability factor is also positive, on a scale of 0 to 1 [2-5].

The goal of a supportability analysis is to determine the context of the socio-economic and environmental conditions against which investment measures will be implemented, as well as the medium- or long-term evolution of an analyzed situation. These variables will effectively determine whether the proposed improvements are supportable for the community, particularly for vulnerable social strata [2].

The calculation of the rate of supportability is made according to the following formula $[1,2]$ :

$$
\mathrm{Rs}=\frac{\mathrm{i}(\mathrm{ep})}{\mathrm{i}(\mathrm{sp})}
$$

where Rs indicates the rate of supportability, $i(e p)$ represents the indicator that exerts pressure, and $\mathrm{i}(\mathrm{sp})$ is the indicator that supports pressure.

In the examples below, we will also use the calculation of the general supportability index, according to the following formula:

$$
I_{s g}=\frac{\sum R_{s}}{n \times I_{s}}
$$

where $I_{s g}$ represents the general supportability index, $R_{S}$ indicates the rate of supportability of the analyzed indicators, $n$ represents the total number of indicators, and $I_{S}$ represents the analyzed indicators. Similarly, the supportability index can be calculated on each factor [2]

The hypothesis is represented by the actual state of the pressures existing on the coastal areas. As we stated before, we will use citizen science in order to identify, test, and validate the hypothesis. The indicators of supportability were calculated based on a survey of 30 respondents who were specifically interested in coastal activities. This survey focused on 16 activities, including 7 economic, 5 environmental, and 4 social activities. This type of random sampling divided the subjects into two layers, and in each layer, a 
sample of 15 respondents was selected proportionally. The division followed the sizing of the sample, considering the population structure of the analyzed area. When dividing into groups, several criteria were considered, such as age, education, social status, religion, etc. Each subject has been assigned a number. The interviews were structured so that each subject could identify the interactions between coastal activities and determine the pressures exerted.

The stratification of the sampling ensured, in the analyzed case, a significant representation of the population, which determines a decrease of the sampling error. The present groups were adequately represented, and the division into subgroups led to a more pronounced heterogeneity. However, it must be said that, in this case, we started from a priori knowledge of the situation, data, and the multicriteria analyses of the coastal management model made by its classical approach. At the same time, in this case of stratified sampling, the procedure was more complex than in simple sampling, due to the need to divide the subjects and divide the subgroups.

\section{Results}

The implementation of a coastal management model in Constanta by introducing a Living Labs concept is the main theme of this research. Initially, the management model was developed in the multi-criteria analysis of the "Mass Tourism Management Model Related to the Impact on the Local Community in Constanta City (Romania)", published in MDPI Inventions on 28 June 2021. In the published paper, the coastal management model was based on the analysis of official statistical data. In this paper, we intend to put the Living Labs concept into action by utilizing data and information gathered from citizens. The hypothesis from which we started the current research is represented by the actual state of the pressures existing on the coastal areas. As we stated before, we used citizen science in order to identify, test, and validate the hypothesis. Thus, in Figure 5, you can see a comparison of the supportability factors related to the indicators provided by the citizens of Constanta and those provided by official sources. Figure 6 depicts a graphical analysis of the calculated coefficients of the supportability factors of coastal zone activities.

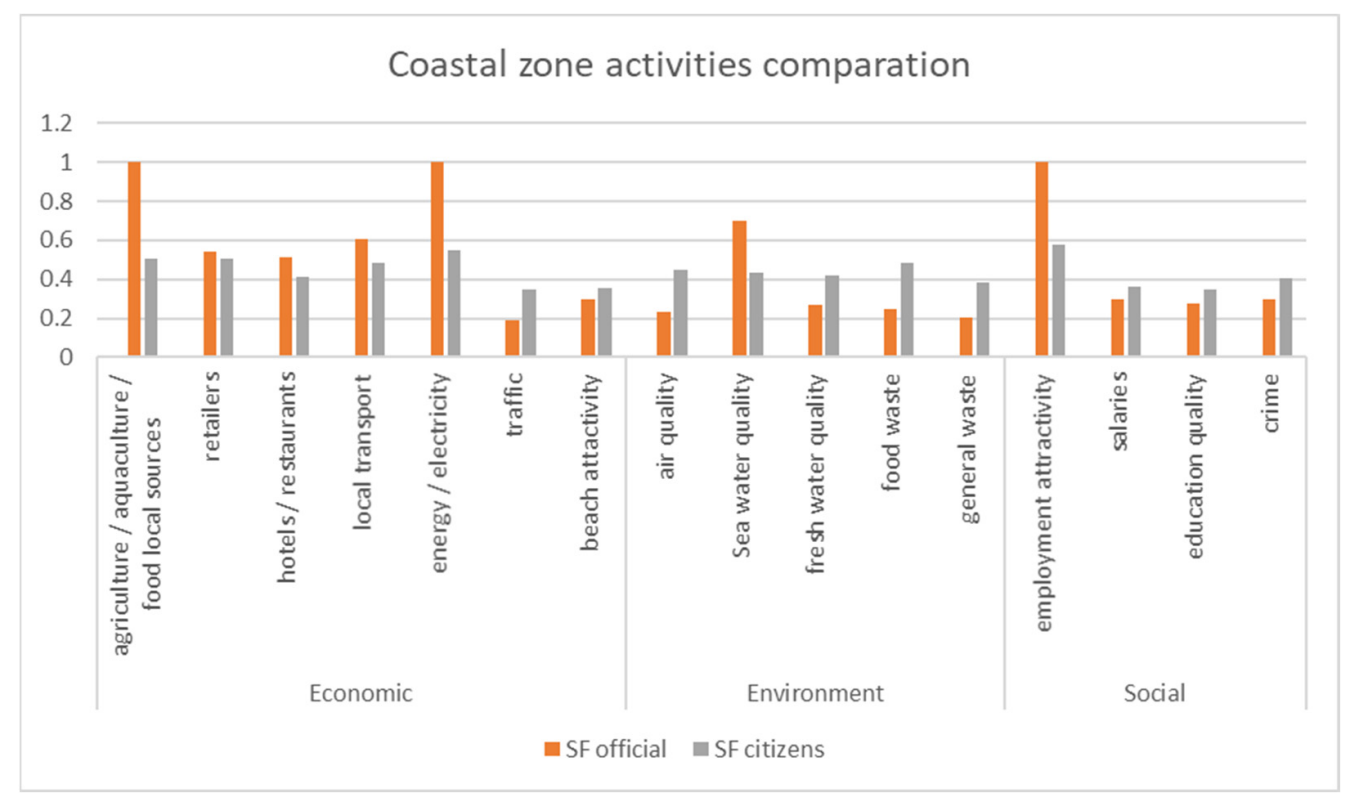

Figure 5. A comparison of the economic, social, and environmental activities that take place in the Constanta coastal area (Romania). 


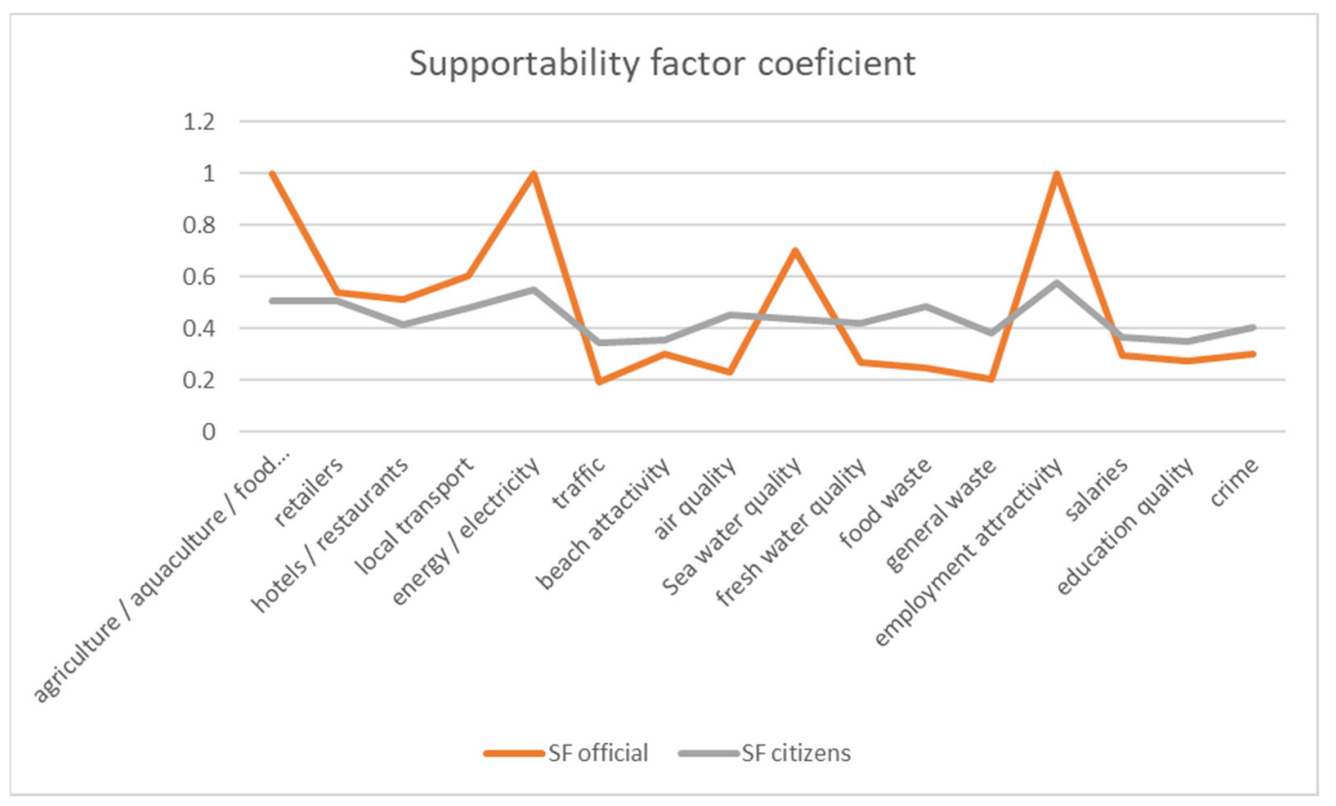

Figure 6. A graphical analysis of the activities in the Constanta coastal area (Romania).

Figures 7-9 show the activity analysis for each of the economic, social, and environmental factors.

Figure 10 depicts the share of the supportability factor calculated by citizens as well as sources provided by public institutions.

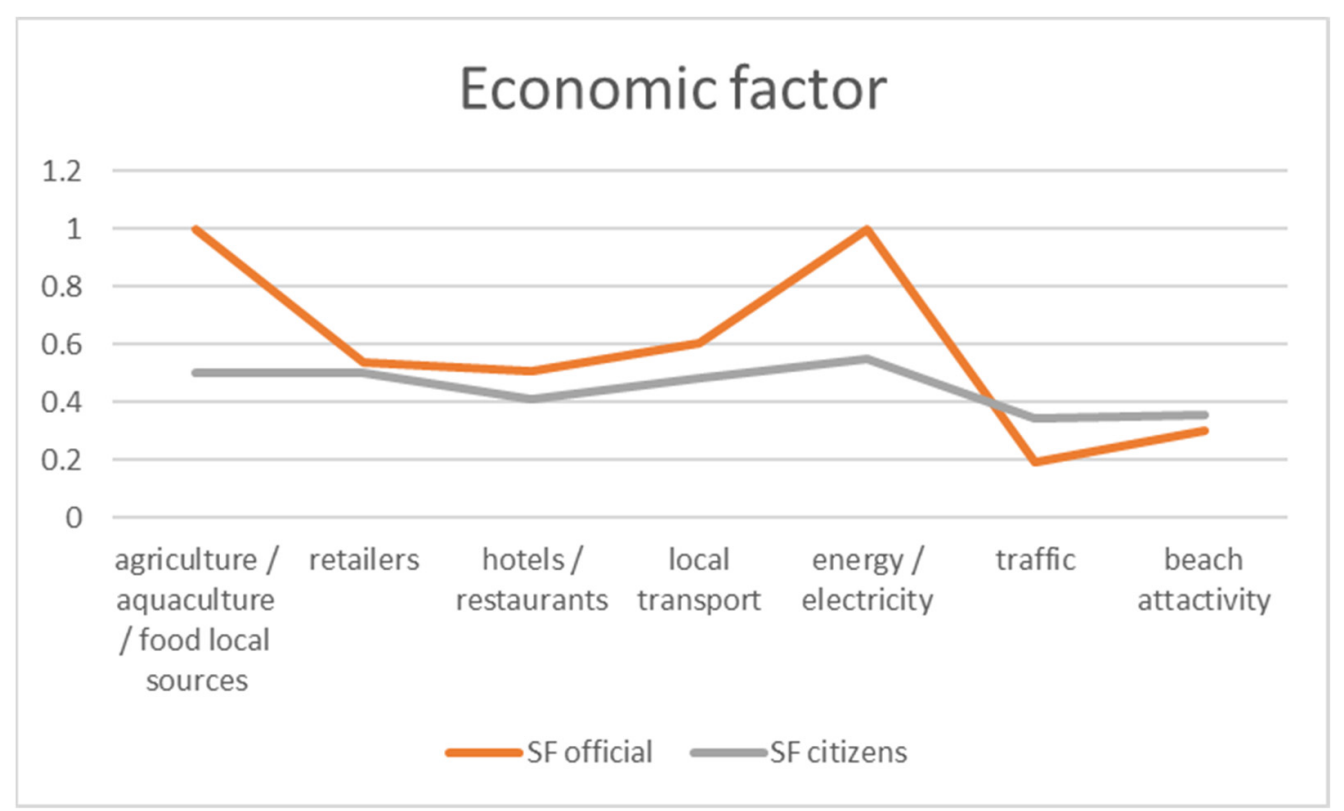

Figure 7. Analysis of economic activities by calculating the coefficient of the supportability factor. 


\section{Social factor}

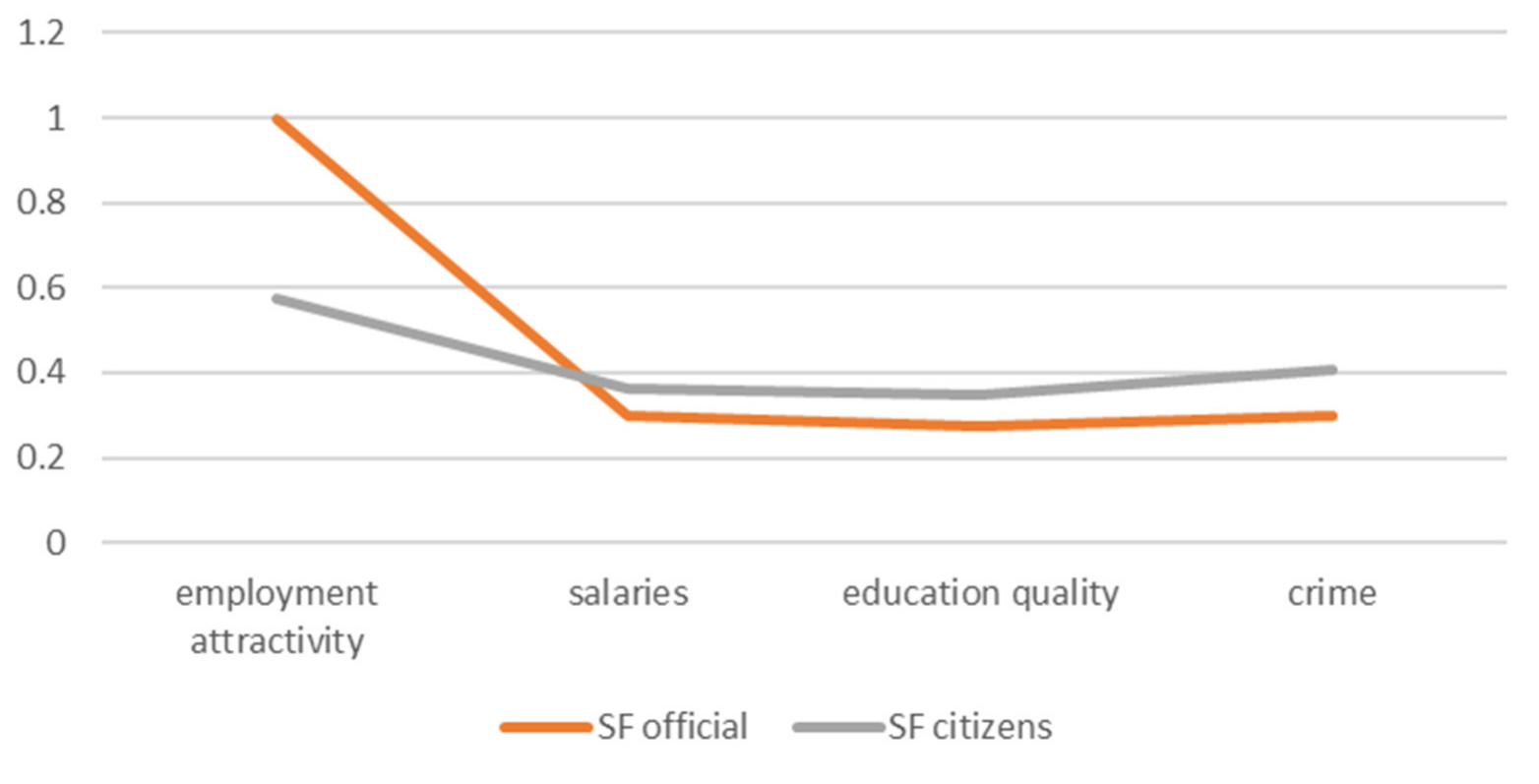

Figure 8. Analysis of social activities by calculating the coefficient of the supportability factor.

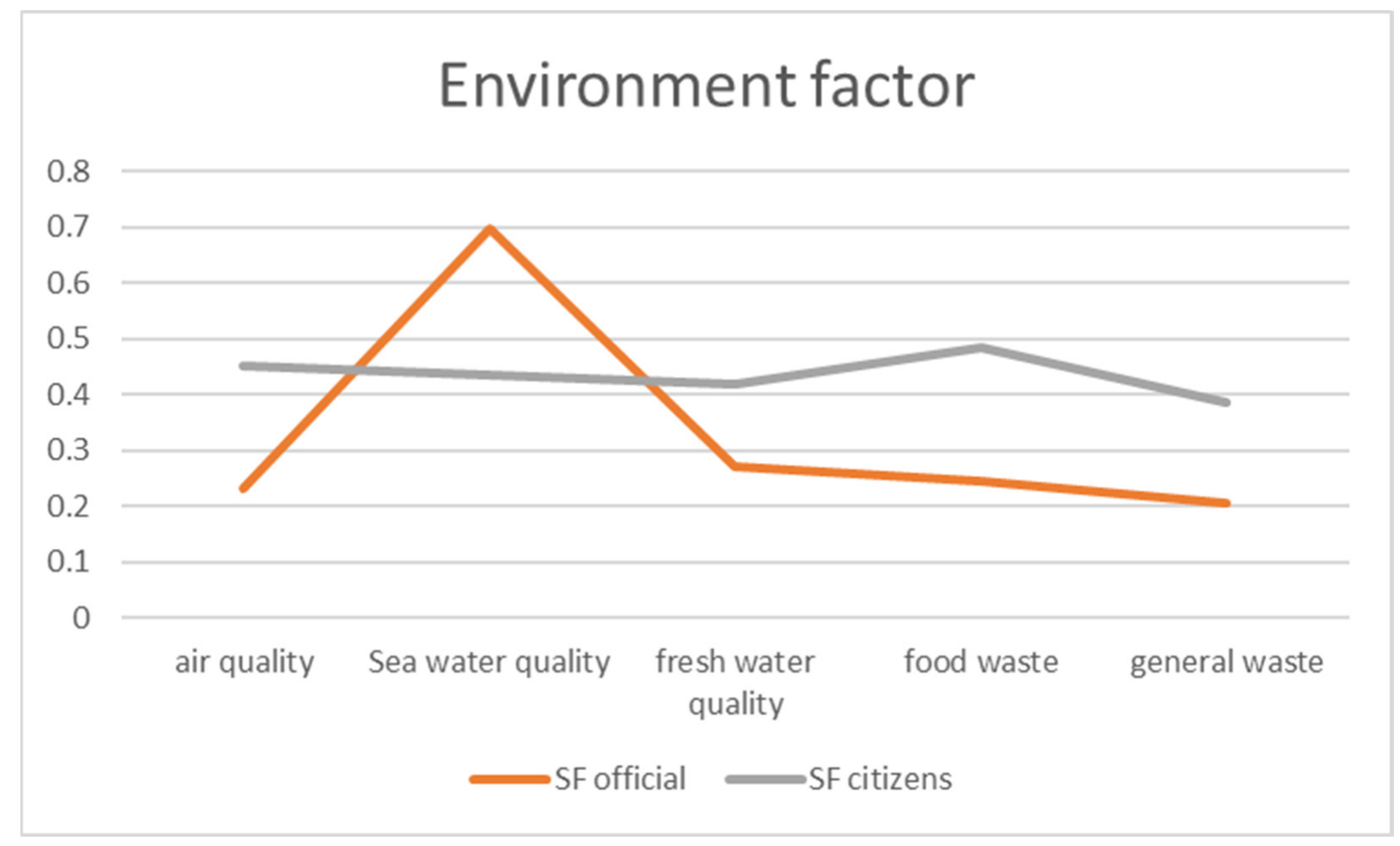

Figure 9. Analysis of environment activities by calculating the coefficient of the supportability factor. 


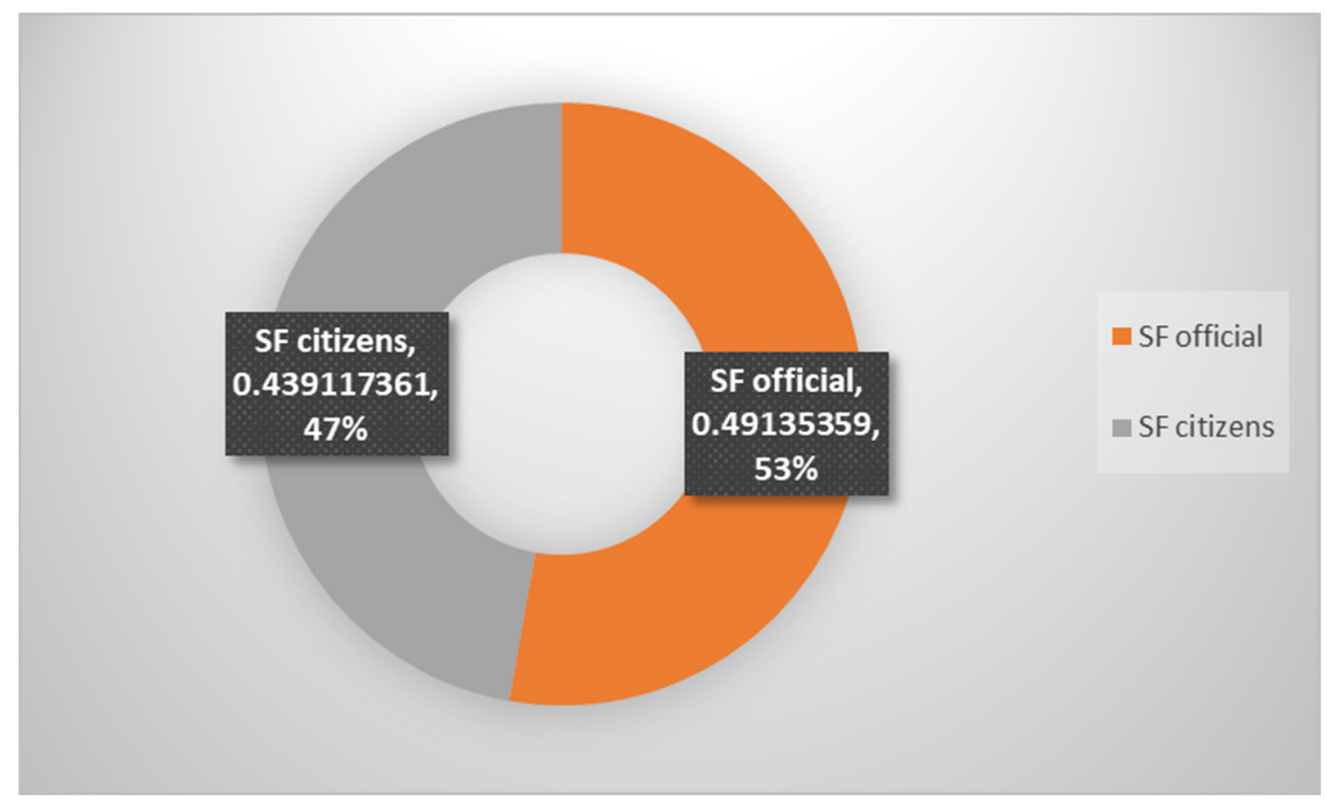

Figure 10. The share of the supportability factor resulting from the calculation of the two coefficients, from public sources and from citizen sources.

\section{Discussion}

This case study refers to the creation of a Living Lab concept in Constanta. The implementation framework of this new concept starts from the observations of the citizens and of the scientific environment, which define, conceptualize, and test the existing vulnerabilities in that area. To create this functional framework, the authors consider it essential to involve citizens, through the data they provide, both in research and development.

A Living Lab is a physical or virtual space where you can solve the economic, social, and environmental challenges for coastal areas by involving different stakeholders. The notion has received increased attention from academia, practitioners, and policymakers in recent years. Therefore, we conducted a systematic review of the literature on Living Labs to understand the complex approaches punctuated by the researchers. As mentioned before, the Living Laboratory is a multidisciplinary "organism" that encompasses multiple fields of research.

The contribution of the article to the scientific-technical knowledge emphasized in the multidisciplinary approach of the Living Laboratory that is discussed within the open innovation paradigms and of the users. Even the literature identifies Living Laboratory workers differently, who apply different methodologies, business models, or tools. This is normal, if we refer to the coastal areas and the fact that they differ by their particularities.

The analysis tried to demonstrate the importance of establishing a Living Lab for the management of the coastal model in Constanta (Romania). The calculation of the supportability coefficient of the analyzed activities reveals significant differences in many cases. Thus, when we examined indicators of employability (social) or bathing water quality, citizens' perceptions differed significantly from official data (environment). Moreover, in the case of economic activities, there were significant differences in opinion between authorities and citizens, particularly regarding the indicators of agriculture/aquaculture/local food and energy/electricity. It is impossible to say with certainty that one source is more credible than the other, especially because, in the field of official statistical data, there are frequently deficient methods of collection or insufficient sources to lend credibility to these types of data.

Even if the data differs in some cases, the analysis of the supportability factor shows that the trend is similar, in the sense that if the coefficient of the supportability factor is increased in the case of some activities or in the case of the analysis of the official data, this is also found in the case of the coefficient of the supportability factor of the data provided 
by citizens. This demonstrates that both authorities' and citizens' perceptions of certain community themes are similar, with the difference being the prioritization of activities within community themes.

In terms of the pressure on activities, according to the analysis, citizens believe that most economic indicators are under more pressure than the authorities believe. In terms of social indicators, both citizens and authorities believe that there is a lot of pressure on these indicators, with the exception of employability, where the authorities believe that jobs are sufficient. Citizens accept this, but believe that employability is not sufficiently diverse and of high quality. In terms of environmental indicators, official data are much more pessimistic than citizen trust, with the latter claiming that there is insufficient access for the cosmos.

A general analysis of the supportability factor reveals that citizens believe that the pressures exerted on coastal zone activities are significantly higher than what the data provided by the authorities show, but the difference between these two calculated values is not very large.

A hypothesis that can be deduced from the analysis made by the citizens, within the stratified sampling, led to results that can offer working tools and ways to improve the existing situations to the authorities but also to the researchers. Stratified sampling techniques are important for researchers who need to understand and design them appropriately. Our results indicate that, in the resulting coastal management model that is closer to the vision of the population, there are sometimes substantial differences from the approach of public institutions. Therefore, the model determined by Living Labs in coastal areas is a viable comparison model for government actions.

\section{Conclusions}

The analysis to introduce the application of the Living Labs concept in the management of the coastal area of Constanta (Romania) shows that these mechanisms can collect creative ideas and realistic approaches to some of the challenges that communities face. Citizens' participation in these structures is advantageous since it includes civil society in making development recommendations in an area. To prove this, we discovered that there were significant differences in opinion between authorities and citizens, particularly regarding the indicators of agriculture/aquaculture/local food and energy/electricity. More than that, a general evaluation of the supportability factor suggests that citizens think that the pressures exerted on coastal zone operations are substantially larger than what the statistics given by the government show, although the discrepancy between these two computed values is not particularly large. From these, we can easily conclude that the Living Labs concept is a useful approach in coastal management and aims to identify, define, develop, test, and validate new approaches to community plans and strategies.

The analysis of the integrated management model of the coastal area, based on economic, social, and environmental indicators, demonstrates the need for the establishment of a Living Lab in Constanta. This concept has the potential to lead to the harmonization of positions between citizens and authorities, as well as the inclusion of all stakeholders, who can contribute to the creation of a coherent framework in the coastal zone.

Decision makers must use innovative governance and encourage stakeholders and the general public to share the data they collect and hold in order for this to be possible. In turn, the authorities must make the databases transparent to citizens and make them easier to access.

Information and communication technology, as well as infrastructure, are required to facilitate new forms of collaboration and co-creation of new innovations among stakeholders. The digitalization of public services can aid in the development of citizen-authority relations.

A coastal Living Lab could be the community's response to the sensitivities and vulnerabilities caused by climate change. Following multi-criteria and multi-sectoral analyses, this new structure can provide dynamic and adequate solutions that are accepted by the community. 


\begin{abstract}
Author Contributions: Conceptualization, C.A. and A.E.M.; methodology, A.E.M.; validation, C.A., A.E.M. and E.R.; formal analysis, C.A.; investigation, A.E.M.; resources, A.E.M. and E.R.; data curation, C.A.; writing—original draft preparation, C.A.; review and editing, E.R.; visualization, C.A.; supervision, A.E.M. and E.R.; project administration, A.E.M.; funding acquisition, E.R. All authors have read and agreed to the published version of the manuscript.

Funding: This work was carried out in the framework of the research project DREAM (Dynamics of the REsources and technological Advance in harvesting Marine renewable energy), supported by the Romanian Executive Agency for Higher Education, Research, Development and Innovation Funding-UEFISCDI, grant number PN-III-P4-ID-PCE-2020-0008.
\end{abstract}

Conflicts of Interest: The authors declare no conflict of interest.

\title{
References
}

1. Anton, C.; Gasparotti, C.; Anton, I.A.; Rusu, E. Implementation of a Coastal Management model in Kinvara Bay at the North Atlantic Ocean. J. Mar. Sci. Eng. 2019, 8, 71. [CrossRef]

2. Anton, C.; Micu, A.E.; Rusu, E. Multi-Criteria Analysis of the Mass Tourism Management Model Related to the Impact on the Local Community in Constanta City (Romania). Inventions 2021, 6, 46. [CrossRef]

3. Yüksel, I. Developing a Multi-Criteria Decision Making Model for PESTEL Analysis. Int. J. Bus. Manag. 2012, 7, 52. [CrossRef]

4. Richardson, J.V., Jr. The library and information economy in Turkmenistan. IFLA J. 2006, 32, 131-139. [CrossRef]

5. Ståhlbröst, A.; Holst, M. The Living Lab Methodology Handbook; LuleGrafiska: Luleå, Sweden, 2012.

6. Rusu, E.; Soares, C.G. Wave energy assessments in the coastal environment of Portugal continental. In Proceedings of the 27th International Conference on Offshore Mechanics and Arctic Engineering-OMAE, Berlin, Germany, 9-13 June 2008 ; Code 76693. Volume 6, pp. 761-772.

7. Bergvall-Kareborn, B.H.M.S.A.; Hoist, M.; Stahlbrost, A. Concept Design with a Living Lab Approach. In Proceedings of the 42nd Hawaii International Conference on System Sciences, Waikoloa, HI, USA, 5-8 January 2009.

8. Fuglsang, L.; Hansen, A.V.; Mergel, I.; Røhnebæk, M.T. Living Labs for Public Sector Innovation: An Integrative Literature Review. Adm. Sci. 2021, 11, 58. [CrossRef]

9. Marine Institute. Characterisation Report Number V Clarinbridge Kinvarra Bay Shellfish Area County Galway. Available online: https:/ / www.housing.gov.ie/sites/default/files/publications/files/filedownload22059en.pdf (accessed on 14 December 2019).

10. Anton, I.A.; Rusu, L.; Anton, C. Nearshore wave dynamics at Mangalia beach simulated by spectral models. J. Mar. Sci. Eng. 2019, 7, 206. [CrossRef]

11. De Graaf van Dinther, R.E. (Ed.) Climate Resilient Urban Areas Governance, design and development in coastal delta cities. In Palgrave Studies in Climate Resilient Societies; Springer International Publishing: Cham, Switserland, 2021; ISBN 978-3-030-57536-6 or 978-3-030-57537-3.

12. Diderich, C. Design Thinking for Strategy, Innovating towards Competitive Advantage; Springer: Richterswil, Switzerland, 2020.

13. Müller-Roterberg, C. Design Thinking for Dummies; John Wiley \& Sons, Inc.: Hoboken, NJ, USA, 2020.

14. Rusu, E.; Conley, D.; Ferreira-Coelho, E. A hybrid framework for predicting waves and longshore currents. J. Mar. Syst. 2008, 69, 59-73. [CrossRef]

15. Ivan, A.; Gasparotti, C.; Rusu, E. Influence of the interactions between waves and currents on the navigation at the entrance of the Danube Delta. J. Environ. Prot. Ecol. 2012, 13, 1673-1682.

16. Anton, C.; Gasparotti, C.; Rusu, E. Identification of the economic pressure on environmental factors in the Romanian coastal zone-case study Eforie. In Proceedings of the 18th International Multidisciplinary Scientific GeoConference Surveying Geology and Mining Ecology Management, SGEM, Albena, Bulgaria, 24 August-2 September 2018; Volume 18, p. 461.

17. Anton, C.; Gasparotti, C.; Rusu, E.; Anton, I.A. Approach to the analysis and evaluation of the strategic intervention options in the Romanian coastal zone taking into account economic, social and environmental factors. In Proceedings of the International Multidisciplinary Scientific GeoConference Surveying Geology and Mining Ecology Management, SGEM, Albena, Bulgaria; 2018; Volume 18, p. 67. Available online: https://www.sgem.org/index.php/elibrary?view=publication\&task=show\&id=1571 (accessed on 30 October 2021).

18. Anton, C.; Gasparotti, C.; Rusu, E. A challenge for the inland navigation-A connection between the Baltic and the Black seas. In Proceedings of the ICTTE Conference, Belgrad, Serbia, 20-21 July 2018.

19. Cheng, E.W.L.; Li, H. Application of ANP in process models: An example of strategic partnering. Build. Environ. 2007, 42, $278-287$. [CrossRef]

20. Dare, C. The UK tour-operating industry: A competitive analysis. J. Vacat. Mark. 2006, 6, 357-367.

21. Saaty, T.L.; Takizawa, M. Dependence and independence: From linear hierarchies to nonlinear networks. Eur. J. Oper. Res. 1986, 26, 229-237. [CrossRef]

22. Shilei, L.; Yong, W. Target-oriented obstacle analysis by PESTEL modeling of energy efficiency retrofit for existing residential buildings in China's northern heating region. Energy Policy 2009, 37, 2098-2101. [CrossRef]

23. Shyur, H.J. COTS evaluation using modified TOPSIS and ANP. Appl. Math. Comput. 2006, 177, 251-259. [CrossRef] 
24. Tzeng, G.H.; Chiang, C.H.; Li, C.W. Evaluating intertwined effects in e-learning programs: A novel hybrid MCDM model based on factor analysis and DEMATEL. Expert Syst. Appl. 2007, 32, 1028-1044. [CrossRef]

25. Vitkiene, E. Questions that have to be answered by a well-managed strategy of coastal recreation and tourism enterprises development. TILTAI 2009, 4, 117-124.

26. $\mathrm{Wu}, \mathrm{W} . \mathrm{W}$. Choosing knowledge management strategies by using a combined ANP and DEMATEL approach. Expert Syst. Appl. 2008, 35, 828-835. [CrossRef]

27. Elomda, B.M.; Hefny, H.A.; Hassan, H.A. An extension of fuzzy decision maps for multi-criteria decision-making. Egypt. Inform. J. 2013, 14, 147-155. [CrossRef]

28. Frynas, J.G.; Mellahi, K. Global Strategic Management; Oxford University Press: Oxford, MS, USA, 2015.

29. Gray, S.A.; Gray, S.; Cox, L.J.; Henly-Shepard, S. Mental modeler: A fuzzy-logic cognitive mapping modeling tool for adaptive environmental management. In Proceedings of the 46th Hawaii International Conference on System Sciences, Wailea, HI, USA, 7-10 January 2013.

30. Healey, N.M. The transition economic of central and eastern Europe: A political, economic, social and technological analysis. Columbia J. World Bus. 1994, 29, 62-70. [CrossRef]

31. Kosko, B. Fuzzy cognitive maps. Int. J. Man-Mach. Stud. 1986, 24, 65-75. [CrossRef] 